\title{
A new efficacy parameter (complete/near complete symptom relief) in allergic rhinitis management: results with a new therapy MP29-02*
}

\author{
Jean Bousquet ${ }^{1}$, Glenis Scadding ${ }^{2}$, David Price ${ }^{3}$, Peter Hellings ${ }^{4}$, Wytske Fokkens ${ }^{5}$, Ullrich Munzel ${ }^{6}$, Claus Bachert $^{7 *}$ \\ From 9th Symposium of Experimental Rhinology and Immunology of the Nose (SERIN 2013) \\ Leuven, Belgium. 21-23 March 2013
}

\section{Background}

It is unclear what constitutes a clinically-meaningful response for allergic rhinitis (AR) outcomes. In a recent survey [1] most experts defined control as being "hardly troubled at all" by each symptom. We propose a new criterion of $\leq 1$ point remaining in each nasal symptom score (Max AM+PM score for each symptom=6) of the reflective total nasal symptom score (rTNSS) to stringently test efficacy and provide an endpoint meaningful to physicians and patients. This criterion has been termed complete/near-to-complete symptom control. Any treatment providing this level of control (patients will feel "cured") should have considerable socioeconomic impact.

\section{Objective}

To compare the proportion of patients achieving $\leq 1$ point remaining in each of the 4 symptoms of the rTNSS (congestion, itching, rhinorrhoea \& sneezing) and the time taken to achieve this response in patients treated with MP29-02* (a novel intranasal formulation of azelastine hydrochloride $[\mathrm{AZE}]$ and fluticasone propionate $[\mathrm{FP}]), \mathrm{FP}$, AZE or placebo (PLA) nasal sprays.

\section{Methods}

610 patients ( $\geq 12$ years old) with moderate-to-severe seasonal AR were randomized into a double-blind, placebocontrolled, 14 day parallel-group trial to receive MP29$02^{*}$, commercially-available AZE or FP nasal sprays or PLA nasal spray (all 1 spray/nostril bid; total daily dose [AZE: $548 \mu \mathrm{g}$, FP: $200 \mu \mathrm{g}$ ]). The primary outcome was change from baseline in rTNSS over 14-days. Time to

${ }^{7}$ Ghent University Hospital, Dept of Oto-rhinolaryngology, Ghent, Belgium Full list of author information is available at the end of the article achieve $\leq 1$ point remaining in each nasal symptom $(\mathrm{AM}+$ PM) of the rTNSS was assessed post-hoc by Kaplan-Meier estimates and log rank tests.

\section{Results}

$17.8 \%$ of MP29-02\% patients ( 1 out of 6 ) achieved this response versus $8.3 \%, 9.2 \%$ and $7.8 \%$ of those treated with AZE, FP and PLA, respectively. MP29-02* patients achieved this response up to 7 days faster than AZE $(\mathrm{p}=0.0152)$ and up to 8 days faster than either FP $(p=0.0262)$ or PLA $(p=0.0094)$. Neither AZE nor FP differed from PLA for this parameter.

\section{Conclusion}

MP29-02* provides faster and more complete symptom control than first-line therapies for AR. One out of 6 moderate to severe AR patients achieved complete/near-tocomplete and uniform symptom relief days faster than either FP or AZE. MP29-02* is the drug of choice for AR treatment since it was the only therapy to rapidly provide such a level of symptom control. This endpoint should become a new standard in assessing the efficacy of current and novel AR therapy.

"Dymista

\section{Author details}

${ }^{1}$ Hopital Arnaud de Villeneuve University Hospital, Montpellier, France. ${ }^{2}$ The Royal National Throat, Nose and Ear Hospital, London, UK. ${ }^{3}$ University of Abderdeen, Dept of General Practice \& Primary Care, Aberdeen, UK.

${ }^{4}$ University Hospitals Leuven, Dept of Otorhinolaryngology, Head and Neck Surgery, Leuven, Belgium. ${ }^{5}$ Academic Medical Center, Dept of

Otorhinolaryngology, Amsterdam, the Netherlands. ${ }^{6}$ Meda Pharma,

Biostatistics \& Market Access, Bad Homburg, Germany. ${ }^{7}$ Ghent University

Hospital, Dept of Oto-rhinolaryngology, Ghent, Belgium.

Published: 16 July 2013 


\section{Reference}

1. Scadding G, et al: Poster. BSACl 201.

doi:10.1186/2045-7022-3-S2-P42

Cite this article as: Bousquet et al: A new efficacy parameter (complete/

near complete symptom relief) in allergic rhinitis management: results with a new therapy MP29-02*. Clinical and Translational Allergy 2013 3(Suppl 2):

P42.

Submit your next manuscript to BioMed Central and take full advantage of:

- Convenient online submission

- Thorough peer review

- No space constraints or color figure charges

- Immediate publication on acceptance

- Inclusion in PubMed, CAS, Scopus and Google Scholar

- Research which is freely available for redistribution

Submit your manuscript at 